Article

\title{
Does Massive Placement of Bicycles Win the Market for the Bicycle-Sharing Company in China?
}

\author{
Jialing Zhao ${ }^{1}$, Hongwei Wang ${ }^{1} * \mathbb{D}$, Yuxin Huang ${ }^{1}$ and Yuan Meng ${ }^{2}$ \\ 1 School of Economics and Management, Tongii University, Shanghai 200092, China; \\ 1810267@tongji.edu.cn (J.Z.); yuxinh@tongji.edu.cn (Y.H.) \\ 2 School of Statistics and Information, Shanghai University of International Business and Economics, \\ Shanghai 200235, China; nancymeng5544@163.com \\ * Correspondence: hwwang@tongji.edu.cn; Tel.: +86-021-65984225
}

Received: 14 March 2020; Accepted: 24 June 2020; Published: 30 June 2020

\begin{abstract}
The rise of bicycle-sharing stimulated companies' investment in a large number of bicycles in the market. However, it is important to balance the massive placement of bicycles in the market and the company's sustainable development. This paper is motivated to identify a strategic balance between market expansion and the sustainable development of the company. Based on the information asymmetry and evolutionary game theory, a tripartite game model was established for the government, enterprise, and consumer. This study identified five evolutionary stability strategies (ESSs) of these three parties under specific conditions by analyzing their decision-making behavior. The results indicated that the number of bicycles in the market placed by a bicycle-sharing enterprise was not directly proportional to its profit. The quantity of bicycles needed on the market was influenced by the government and consumers. It also found that government regulation plays a dominant role in the development of the bicycle-sharing company regarding the number of bicycles needed in the market.
\end{abstract}

Keywords: sharing economy; bicycle-sharing; information asymmetry; evolutionary game theory

\section{Introduction}

Since the first bicycle-sharing system launched in Amsterdam, The Netherlands, in 1965, the bicyclesharing system has shown several advantages, including flexible mobility, physical activity, reduced congestion, emissions, and fuel use, popular all over the world [1]. There are four generations of bicycle-sharing: free bike systems, coin-deposit systems, information technology-based systems [2], and multimodal systems that are demand-responsive and adaptive to user needs [3,4]. With its green, environment-friendly, and convenient travel mode, bicycle-sharing has won the favor of the society and the support of the government [5].

Since its launch in 2014, bicycle-sharing has become popular among the population. Bicycle-sharing does not require an upfront investment or maintenance costs and frees the consumers from the worries of the bicycle being stolen. It only charges a small amount of rental fee and operating fee, making it attractive to the consumers [6]. Price had an impact on residents' travel patterns, with residents showing an inclination toward the bicycle-sharing system when making short-distance trips if it was quickly found, in [7]. Bicycle-sharing has reduced traffic flow, energy consumption, and harmful gas emissions, improving public health and promoting economic growth [8]. These advantages bolster the development of the bicycle-sharing company. Since the success of Ofo.com and Mobike.com, a great number of bicycle-sharing enterprises has started to rise. During the boom of bicycle-sharing development, companies usually adopt large-volume delivery strategies that have exposed problems in company strategy. It is reported that more than 70 bicycle-sharing companies were founded in the 
market from 2016 to 2018 in China, many of which didn't survive. This is related to parking problems and maintenance and recycling problems caused by the large number of bicycle-sharing. Therefore, the placement behavior and sustainable development of bicycle-sharing companies have come into the spotlight.

Although there has been plenty of studies on the opinion model, most of them focus on the demand of the bicycle-sharing system [2], inventory routing [9-11], bicycle-sharing stations [3,12,13], bicycle-sharing usage, and rebalance [14-18]. What they ignore is the fact that while bicycle-sharing can reduce traffic congestion and pollution problems in downtown areas [15], the development of bicycle-sharing has also exposed several problems. Parking problems, company operation problems, and urban policies are all factors that made it difficult for bicycle-sharing companies to sustain in the market. One of the significant problems in the bicycle-sharing system design is the estimation of the potential demand of the service, especially in countries where this type of system has not yet been implemented [2]. There are about 1.03 million bicycles in Wuhan, which has exceeded the urban non-motor vehicle space carrying capacity. In Shanghai, Beijing, and other metropolitan cities, the number of bicycles in the city has exceeded the actual demand. Due to the large-scale placement of bicycles, a large number of bicycles has been destroyed without repair, randomly parked and released, crowding lanes, followed by other problems. This situation is named "bicycle siege," or "bicycle cemetery." Users can pick up a bicycle from the station and use it for short-distance travel, then leave it at another station, not necessarily the same place where the trip starts. Consequently, the placement of the bicycles usually results in some docking stations being full and others being empty. An excessive number of bicycle-sharing can occupy a significant amount of roadway surface and cause trouble for pedestrians and auto-vehicle drivers $[19,20]$. The issue of the massive placement of bicycles is particularly important in the company's operating strategy. These issues have become a "bottleneck" to the sustainable development of the bicycle-sharing enterprises: the fact that the convenient and sustainable way of travel has gradually become inconvenient and unsustainable makes it difficult to make profits. Thus, finding the balance between the optimal strategy of bicycle placement and the sustainable development strategy for the company is needed.

Inspired by the biological evolutionary process, the evolutionary game theory combines game theory with dynamic evolution process analysis and focuses more on the dynamics of strategy change as influenced by the strategy frequency in the population [21]. The evolutionary game theory is widely used in the study of bicycle-sharing regarding bicycle placement decisions. Previous studies have shown that in the two-party game model between the consumers and the bicycle-sharing companies, the enterprises can choose an appropriate reward and penalty system to solve the problem of bicycle parking guiding the users to civilize parking [22]. The same conclusion was reached after introducing the government into the construction of the evolutionary game model between the government and the bicycle-sharing companies and the bicycle-sharing companies with the consumers [23-25]. It is believed that the government's financial subsidy is conducive to improving the service level and user satisfaction of public bicycle enterprises [26]. Bicycle-sharing, as a new economic model, could still suffer from market-failure issues even after the introduction of government intervention. Thus, the tripartite game relationship was constructed from three aspects: the government's utility maximization, corporate profit maximization, and user satisfaction maximization. Based on the model, the strategies to sustain the organic growth of the company were identified.

The purpose of this study was to model the relationship between the large number of bicycles placed by the bicycle-sharing company and its sustainable development. The paper has several contributions. Firstly, aiming at the placement of the bicycles, an evolutionary game model for the government, bicycle-sharing enterprise, and consumer is established, and the optimal strategy selection of the three parties in the process of standardized development of bicycle-sharing is discussed. Thus, the study enriches the understanding of balanced development of bicycle-sharing supported by evidence for the sustainability of the sharing economy. Secondly, it can provide practical implications for the government and enterprises regarding how they could coordinate and formulate the developing 
strategy of bicycle-sharing, sustain the balance of interests, and maintain the sustainable development of the sharing economy. The significance of this study is to find the balance between the placement of bicycles in the market and sustainable economic development. The study will then help the government formulate a sustainable economic development strategy, promote the "positive external effects" of bicycle-sharing companies, and facilitate consumers' daily travel.

The remainder of this paper is organized as follows: analysis of the evolutionary game model in Section 2, followed by discussions in Section 3. Section 4 is conclusions.

\section{Materials and Methods}

\subsection{Model of the Evolutionary Game}

The direct stakeholders of overspending in the bicycle-sharing market include the government, bicycle-sharing enterprise, and consumer. From the perspective of the government, the government can impose a penalty and monitor the number of bicycles invested (hereinafter referred to as "supervision" $U_{1}$ ). It is also possible to choose not to monitor (hereinafter referred to as "no supervision" $U_{2}$ ) the market taking into consideration the cost and difficulty of supervision. For the bicycle-sharing enterprise, an enterprise is likely to invest in a large number of bikes (hereinafter referred to as "massive placement" $M_{1}$ ) to wantonly seize the consumers and obtain competitive advantages in the market. It may also consider issues such as upfront costs, operation costs, and maintenance costs to deliver on-demand (hereinafter referred to as "controlled placement" $M_{2}$ ). As for the consumer, they may ride the bicycle (hereinafter referred to as "consumption" $E_{1}$ ) or they may not ride it (hereinafter referred to as "no consumption" $E_{2}$ ). In this study, we propose the following prerequisites. All three players are finite rational people, and due to the information asymmetry, their decisions are likely to affect the decisions of other subjects. At the same time, these three parties will judge the strategies of other players through trial and error and historical experience and then make their own decisions. The product of unit price and quantity after massive bicycle placement is greater than the product of unit price and quantity after controlled bicycle placement. We define market stability as an achievement to either of the following situations: the government chooses a regulatory strategy or the company's orderly release of vehicles in government-unregulated conditions.

The following notation is used in the model:

$C=$ the cost of the government to regulate the bicycle-sharing market;

$F=$ the fines of the government for the enterprise's massive delivery;

$I_{1}=$ the quantitative indicators of the beneficial effects on the government for the government's policies and regulations or the measures implemented to the society's best stable state (as a constant, can be given a large number);

$I_{2}=$ a quantitative indicator of the adverse effects of social unrest on the government (as a constant);

$G_{1}=$ the gain of the bicycle-sharing enterprise for controlled delivered bicycle-sharing;

$G_{2}=$ the gain of the bicycle-sharing enterprise for massive delivered bicycle-sharing;

$Q_{1}=$ the used number of bicycle-sharing when the bicycle-sharing enterprise launched bicycles in controlled;

$Q_{2}=$ the used number of bicycle-sharing when the bicycle-sharing enterprise launched bicycles unorderly;

$P_{1}=$ the used price of bicycle-sharing when the bicycle-sharing enterprise put bicycle in order;

$P_{2}=$ the used price of bicycle-sharing when the bicycle-sharing enterprise put bicycle unorderly;

$G_{3}=$ the consumer's gain of used bicycles when the bicycle-sharing enterprise put a bicycle in order;

$G_{4}=$ the consumer's gain of used bicycles when the bicycle-sharing enterprise put bicycle unorderly; 
$I_{3}=$ the quantitative indicators of the beneficial effects on the consumer for the government's policies and regulations or the measures implemented on the society's best stable state (as a constant, can be given a large number);

$I_{4}=$ a quantitative indicator of the adverse effects of social unrest on the consumer (as a constant).

This paper investigates the evolutionary game between the government, the enterprise, and the consumer under the asymmetric situation. Every player has two strategies that add up to eight sets of policy combinations, and the extended type of the game between them is depicted in Figure 1 . Let $x$ be the possibility of the government taking a strategy to monitor the bicycle-sharing market. Then, $1-x$ is the possibility of the government not taking any measures. $x$ satisfies the condition of $0 \leq x \leq 1$. Similarly, $y$ represents the possibility of the enterprise unlimitedly placing the bicycles into the market, and then $1-y$ represents the possibility of the enterprise orderly putting the bicycles into the market. $y$ satisfies the condition of $0 \leq y \leq 1$. $z$ represents the possibility of the consumer using bicycle-sharing, and $1-z$ is defined as the possibility of the consumer not using bicycle-sharing. $z$ satisfies the condition of $0 \leq z \leq 1$.

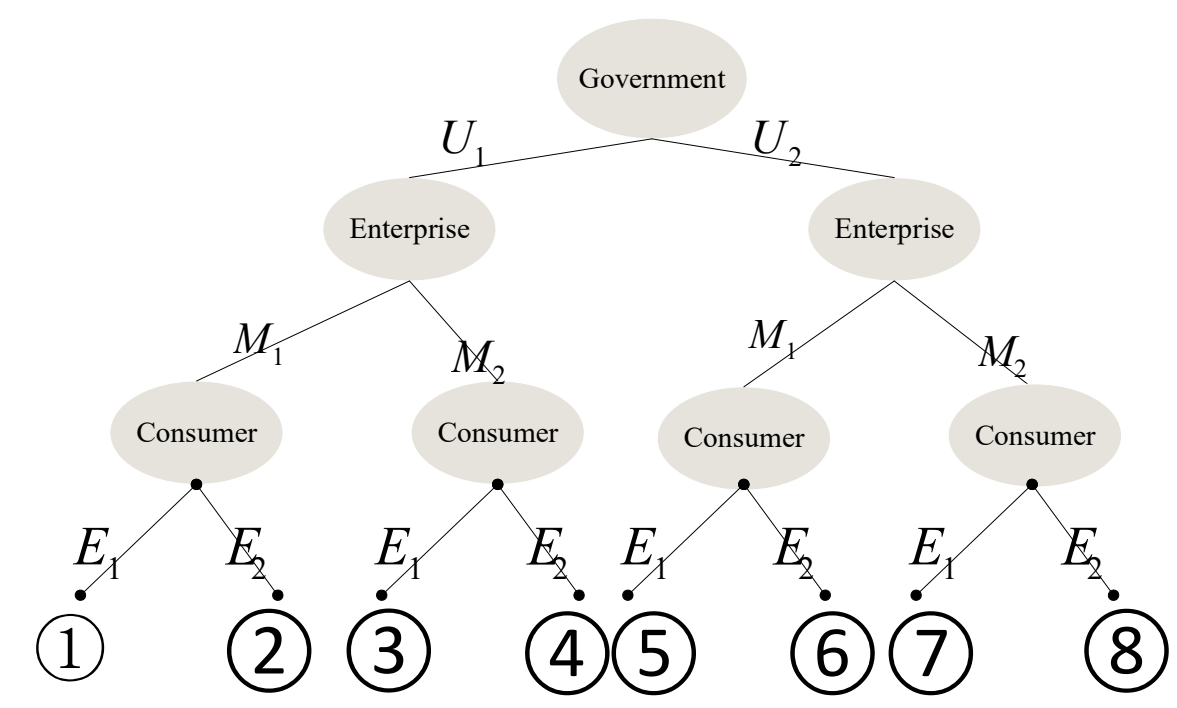

Figure 1. The extended type of the game between the government, enterprise, and consumer. $U_{1}$ and $U_{2}$ mean "supervision" and "no supervision", $M_{1}$ and $M_{2}$ mean "massive placement" and "controlled placement", $E_{1}$ and $E_{2}$ mean "consumption" and "no consumption".

In the eight sets of policy combinations, the profit functions of the three participants are different. When the government chooses "supervision", the enterprise chooses "massive placement", and the consumer chooses "consumption", the decision choice of the three parties is $\left(U_{1}, M_{1}, E_{1}\right)$. When the enterprise delivers the bicycles chaotically, and the consumer uses the bicycles, the government must pay for regulatory actions. Thus, the government can obtain a good reputation by regulating the market. Although the enterprise may make profits by disorderly placing the bicycles, it also needs to face the possibility of a bad reputation and government penalty. On the one hand, though consumers using bicycles need to pay the rental fees, they could benefit from the market stability brought by government policy supervision. On the other hand, when the bicycle-sharing company places a large number of bicycles around the city, the bicycles can be quickly found and the search cost of the consumer is reduced. The profit of the government is $F+I_{1}-C$, the profit of the enterprise is $P_{2} Q_{2}+G_{2}-F$, and the consumer's utility is $G_{3}+I_{3}-P_{2} Q_{2}$. In this way, we get the profit of every policy combinations in Table 1. 
Table 1. Benefit matrix.

\begin{tabular}{|c|c|c|c|c|c|}
\hline & & & & \multicolumn{2}{|c|}{ Consumer } \\
\hline & & & & $E_{1}(z)$ & $E_{2}(1-z)$ \\
\hline \multirow{7}{*}{ Government } & $U_{1}(x)$ & Enterprise & $M_{1}(y)$ & $\begin{array}{c}F+I_{1}-C \\
P_{2} Q_{2}+G_{2}-F \\
G_{3}+I_{3}-P_{2} Q_{2} \\
I_{1}-C\end{array}$ & $\begin{array}{c}F+I_{1}-C \\
G_{2}-F \\
I_{3} \\
I_{1}-C\end{array}$ \\
\hline & \multirow{6}{*}{$U_{2}(1-x)$} & \multirow{6}{*}{ Enterprise } & $M_{2}(1-y)$ & $P_{1} Q_{1}+G_{1}$ & $G_{1}$ \\
\hline & & & & $\begin{array}{c}G_{3}+I_{3}-P_{1} Q_{1} \\
-I_{2}\end{array}$ & $\begin{array}{c}I_{3} \\
-I_{2}\end{array}$ \\
\hline & & & $M_{1}(y)$ & $P_{2} Q_{2}+G_{2}$ & $G_{2}$ \\
\hline & & & & $G_{3}-P_{2} Q_{2}-I_{4}$ & $-I_{4}$ \\
\hline & & & $M_{2}(1-y)$ & $P_{1} Q_{1}+G_{1}$ & $G_{1}$ \\
\hline & & & & $G_{3}-P_{1} Q_{1}+I_{3}$ & $I_{3}$ \\
\hline
\end{tabular}

\subsection{Equilibrium Analysis of the Evolutionary Game}

The payoff matrix consisting of different strategy combinations of the government, the enterprise, and the consumer is listed in Table 1 . In this paper, $W_{1 Y}, W_{2 Y}$, and $W_{3 Y}$ are used to denote the expected profits of the government, enterprise, and consumer. Then, we define $\bar{W} 1, \bar{W} 2$, and $\bar{W} 3$ as the average benefit of the government, enterprise, and consumer, respectively.

$$
\begin{gathered}
W_{1 Y}=y z\left(F+I_{1}-C\right)+y(1-z)\left(F+I_{1}-C\right)+(1-y) z\left(I_{1}-C\right)+(1-y)(1-z)\left(I_{1}-C\right), \\
=y\left(F+I_{1}-C\right)+(1-y)\left(I_{1}-C\right) \\
\overline{W_{1}}=x\left[y\left(F+I_{1}-C\right)+(1-y)\left(I_{1}-C\right)\right]+(1-x)\left[y z\left(-I_{2}\right)+y(1-z)\left(-I_{2}\right)+(1-y) z I_{1}+(1-y)(1-z) I_{1}\right], \\
=x y\left(F+I_{1}+I_{2}\right)+(1-y) I_{1}-x I_{1}-y I_{2} \\
W_{2 Y}=x z\left(P_{2} Q_{2}+G_{2}-F\right)+x(1-z)\left(G_{2}-F\right)+(1-x) z\left(P_{2} Q_{2}+G_{2}\right)+(1-x)(1-z) G_{2}, \\
=G_{2}+z P_{2} Q_{2}-x F \\
\overline{W_{2}}=y\left(G_{2}+z P_{2} Q_{2}-x F\right)+(1-y)\left[x z\left(P_{1} Q_{1}+G_{1}\right)+x(1-z) G_{1}+(1-x) z\left(P_{1} Q_{1}+G_{1}\right)+(1-x)(1-z) G_{1},\right. \\
=y\left(z P_{2} Q_{2}+G_{2}-x F\right)+(1-y) G_{1}+(1-y) z P_{1} Q_{1} \\
=x y\left(G_{4}+I_{3}-P_{2} Q_{2}\right)+x(1-y)\left(G_{3}+I_{3}-P_{1} Q_{1}\right)+(1-x) y\left(G_{4}-P_{2} Q_{2}-I_{4}\right)+(1-x)(1-y)\left(G_{3}-P_{1} Q_{1}+I_{3}\right) \\
=y\left(G_{4}-P_{2} Q_{2}\right)+x y I_{3}+(1-y)\left(G_{3}-P_{1} Q_{1}\right)+(1-y) I_{3}+(1-x) y I_{4} \\
\quad \overline{W_{3}} \quad=z\left[y\left(G_{4}-P_{2} Q_{2}\right)+x y I_{3}+(1-y)\left(G_{3}-P_{1} Q_{1}\right)+(1-y) I_{3}+(1-x) y I_{4}\right]+ \\
\quad(1-z)\left[x y I_{3}+x(1-y) I_{3}+(1-x) y\left(-I_{4}\right)+(1-x)(1-y) I_{3}\right] \\
\quad=z y\left(G_{4}-P_{2} Q_{2}\right)+z(1-y)\left(G_{3}-P_{1} Q_{1}\right)-(1-x) y I_{4}+(1+x y-y) I_{3},
\end{gathered}
$$

According to the Malthusian equation, the quantity's growth rate of strategy selected by players should equal its fitness minus its average fitness. Then the duplicated dynamic equations of $W_{1 Y}$, selected by the government, are given by:

$$
\begin{gathered}
F(x)=\frac{d x}{d t}=x\left(W_{1 Y}-\overline{W_{1}}\right)=x(1-x)\left[y\left(F+I_{2}+I_{1}\right)-C\right], \\
\frac{d F(x)}{d x}=(1-2 x)\left[y\left(F+I_{2}+I_{1}\right)-C\right],
\end{gathered}
$$

We can use the duplicated dynamic equation to calculate the evolution process of government strategic choice. Then we can obtain the equilibrium point and evolutionary stability strategies (ESSs) of the evolutionary game. If $\frac{d F(x)}{d x}<0$, we find the ESS.

(1) When $y=C_{1} /\left(F+I_{2}+I_{1}\right), F(x) \equiv 0$. That means all the levels are stable, and there is no ESS. 
(2) When $y>C_{1} /\left(F+I_{2}+I_{1}\right),\left.\frac{d F(x)}{d x}\right|_{x=0}>0$ and $\left.\frac{d F(x)}{d x}\right|_{x=1}<0, x=1$ is the ESS of the government's strategy selection.

(3) When $y<C_{1} /\left(F+I_{2}+I_{1}\right),\left.\frac{d F(x)}{d x}\right|_{x=0}<0$ and $\left.\frac{d F(x)}{d x}\right|_{x=1}>0, x=0$ is the ESS of the government's strategy selection.

The government's duplicated dynamic trend is depicted in Figure 2.

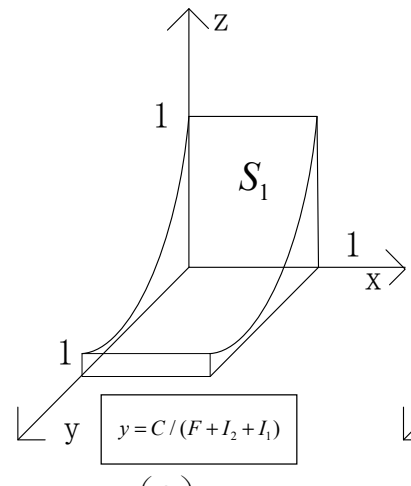

(a)

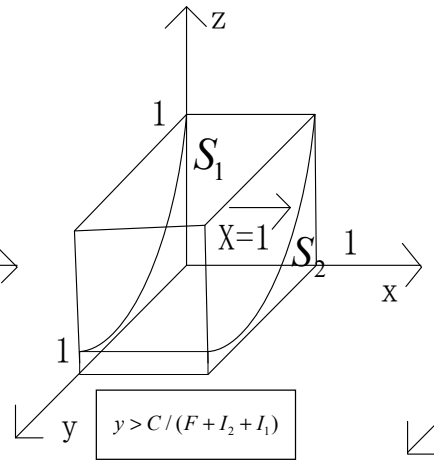

(b)

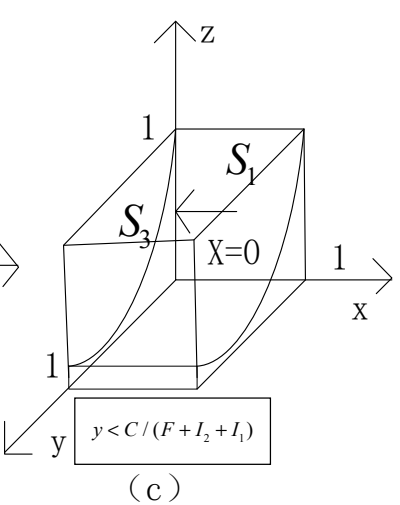

(c)

Figure 2. The evolutionary graph of the government (Diagrams (a-c) response to Scenarios 1, 2 and 3, respectively).

In the same way, we can get an equilibrium point and ESS of the evolutionary course of the enterprise and the consumer.

$$
\begin{gathered}
F(y)=\frac{d y}{d t}=y\left(W_{2 Y}-\overline{W_{2}}\right)=y(1-y)\left[z\left(P_{2} Q_{2}-P_{1} Q_{1}\right)+G_{2}-G_{1}-x F\right], \\
\frac{d F(y)}{d y}=(1-2 y)\left[z\left(P_{2} Q_{2}-P_{1} Q_{1}\right)+G_{2}-G_{1}-x F\right],
\end{gathered}
$$

(1) When $z=\left(G_{2}-G_{1}-x F\right) /\left(P_{2} Q_{2}-P_{1} Q_{1}\right), F(y) \equiv 0$. That means all the levels are stable, and there is no ESS.

(2) When $z>\left(G_{2}-G_{1}-x F\right) /\left(P_{2} Q_{2}-P_{1} Q_{1}\right),\left.\frac{d F(y)}{d y}\right|_{y=0}>0$ and $\left.\frac{d F(y)}{d y}\right|_{y=1}<0 . y=1$ is the ESS of the enterprise's strategy selection.

(3) When $z<\left(G_{2}-G_{1}-x F\right) /\left(P_{2} Q_{2}-P_{1} Q_{1}\right)$, and $\left.\frac{d F(y)}{d y}\right|_{y=1}>0 . y=0$ is the ESS of the enterprise's strategy selection.

The enterprise's duplicated dynamic trend is depicted in Figure 3.

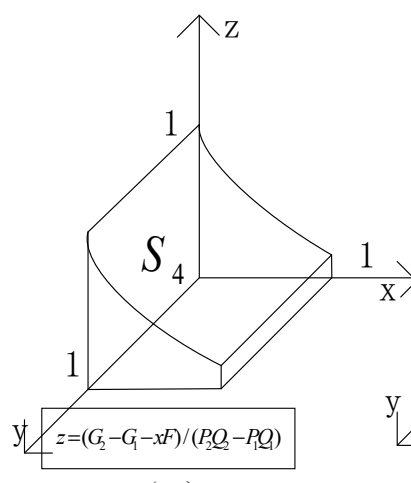

(a)

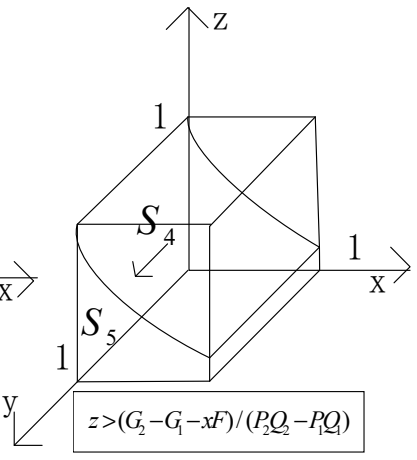

(b)

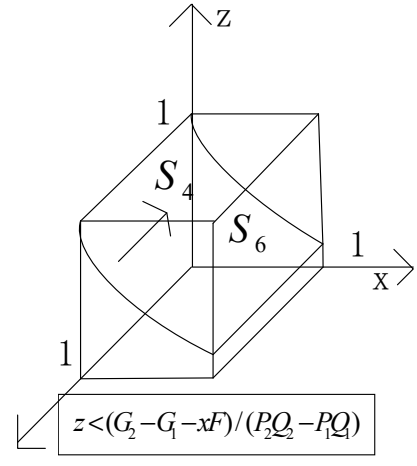

(c)

Figure 3. The evolutionary graph of the enterprise (Diagrams $(\mathbf{a}-\mathbf{c})$ response to Scenarios 1, 2 and 3, respectively). 
Therefore, the replicator dynamics equation of the consumer:

$$
\begin{aligned}
F(z) & =\frac{d z}{d t}=z\left(W_{3 Y}-\overline{W_{3}}\right)=z(1-z)\left[y\left(G_{4}-P_{2} Q_{2}\right)+(1-y)\left(G_{3}-P_{1} Q_{1}\right)\right] \\
& =z(1-z)\left[y\left(G_{4}-G_{3}-P_{2} Q_{2}+P_{1} Q_{1}\right)+G_{3}-P_{1} Q_{1}\right]
\end{aligned}
$$

(1) When $y=\left(P_{1} Q_{1}-G_{3}\right) /\left(G_{4}-G_{3}-P_{2} Q_{2}+P_{1} Q_{1}\right), F(z) \equiv 0$. That means all the levels are stable.

(2) When $y \neq\left(P_{1} Q_{1}-G_{3}\right) /\left(G_{4}-G_{3}-P_{2} Q_{2}+P_{1} Q_{1}\right)$, let $F(z)=0$ and $z=0, z=1$ is the ESS of the consumer's strategy selection.

The derivative of the replicator dynamics equation of $z$ can be calculated as below:

$$
\frac{d F(z)}{d z}=(1-2 z)\left[y\left(G_{4}-G_{3}-P_{2} Q_{2}+P_{1} Q_{1}\right)+G_{3}-P_{1} Q_{1}\right]
$$

(3) When $y>\left(P_{1} Q_{1}-G_{3}\right) /\left(G_{4}-G_{3}-P_{2} Q_{2}+P_{1} Q_{1}\right),\left.\frac{d F(z)}{d z}\right|_{z=0}>0,\left.\frac{d F(z)}{d z}\right|_{z=1}<0, z=1$ is the ESS of the consumer's strategy selection.

(4) When $y<\left(P_{1} Q_{1}-G_{3}\right) /\left(G_{4}-G_{3}-P_{2} Q_{2}+P_{1} Q_{1}\right),\left.\frac{d F(z)}{d z}\right|_{z=0}<0,\left.\frac{d F(z)}{d z}\right|_{z=1}>0, z=0$ is the ESS of the consumer's strategy selection.

The consumer's duplicated dynamic trend is depicted in Figure 4.

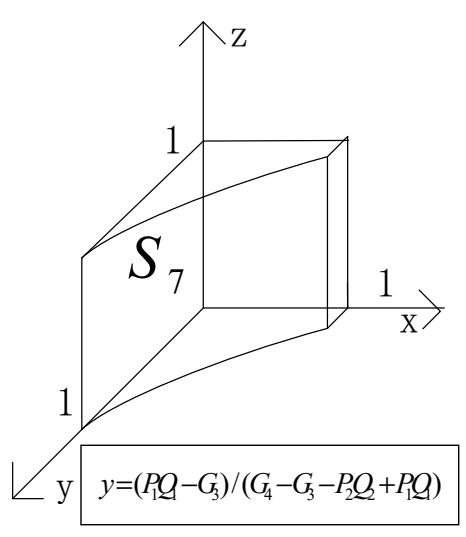

(a)

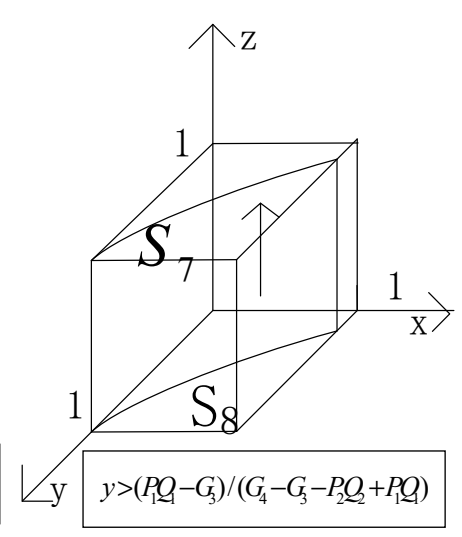

(b)

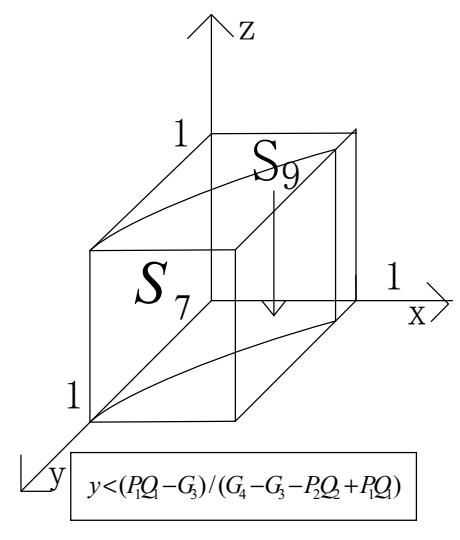

(a)

Figure 4. The evolutionary graph of the consumer (Diagrams $(\mathbf{a}-\mathbf{c})$ response to Scenarios 1, 3 and 4, respectively).

Since the reflective, dynamic equation system in evolutionary games reflects the dynamics of the population, the equilibrium point sought is not necessarily the ESS. The ESS must possess the ability to resist the error or deviation caused by bounded rationality [27]. According to Esmaeili et al. (2016), the ESS point of the evolutionary game is obtained by analyzing the local stability of the Jacobian matrix of the dynamic system [28]. Taking the derivatives of $x, y$, and $z$ with the replicator dynamic equation in Equation (8), Equation (10), and Equation (12) to determine the final ESS in the game, then the Jacobian $\left(J_{(x, y, z)}\right)$ matrix can be obtained as follows:

$$
\begin{aligned}
J_{(x, y, z)} & =\left[\begin{array}{lll}
\frac{\partial X}{\partial x} & \frac{\partial X}{\partial y} & \frac{\partial X}{\partial z} \\
\frac{\partial Y}{\partial x} & \frac{\partial Y}{\partial y} & \frac{\partial Y}{\partial z} \\
\frac{\partial Z}{\partial x} & \frac{\partial Z}{\partial y} & \frac{\partial Z}{\partial z}
\end{array}\right] \\
= & {\left[\begin{array}{ccc}
(1-2 x)\left(y v_{1}-C\right) & x(1-x) v_{1} & \\
-y F(1-y) & (1-2 y)\left(z v_{2}+v_{4}-x F\right) & y(1-y) v_{2} \\
0 & z(1-z) v_{3} & (1-2 z)\left(y v_{3}+v_{6}\right)
\end{array}\right] }
\end{aligned}
$$

where

$$
v_{1}=F+I_{1}+I_{2}>0
$$




$$
\begin{gathered}
v_{2}=P_{2} Q_{2}-P_{1} Q_{1}>0, \\
v_{3}=G_{4}-G_{3}-P_{2} Q_{2}+P_{1} Q_{1}>0, \\
v_{4}=G_{2}-G_{1}>0, \\
v_{5}=G_{2}-G_{1}-F, \\
v_{6}=G_{3}-P_{1} Q_{1}>0 .
\end{gathered}
$$

\begin{tabular}{|c|c|c|c|c|}
\hline $\begin{array}{l}\text { Equilibrium Point } \\
\qquad(x, y, z)\end{array}$ & $\begin{array}{c}\text { Determinant } \\
\text { Symbol of } J(x, y, z)\end{array}$ & Trace Symbol of $J(x, y, z)$ & Results & Stability Condition \\
\hline$(0,0,0)$ & - & $\#$ & Saddle Point & \\
\hline \multirow{2}{*}{$(0,0,1)$} & + & - & ESS & $-C+v_{2}+v_{4}-v_{6}<0$ \\
\hline & + & + & Instability & $-C+v_{2}+v_{4}-v_{6}>0$ \\
\hline$(0,1,0)$ & - & $\#$ & Saddle Point & \\
\hline \multirow[t]{2}{*}{$(1,0,0)$} & + & + & Instability & $\begin{array}{c}v_{5}>0 \\
C+v_{5}+v_{6}>0\end{array}$ \\
\hline & - & & Saddle Point & $v_{5}<0$ \\
\hline \multirow{2}{*}{$(0,1,1)$} & + & - & ESS & $v_{1}-2 v_{2}-v_{4}<0$ \\
\hline & + & + & Instability & $v_{1}-2 v_{2}-v_{4}>0$ \\
\hline \multirow{3}{*}{$(1,0,1)$} & + & - & ESS & $\begin{array}{c}v_{2}+v_{5}<0 \\
C+v_{2}+v_{5}-v_{6}<0\end{array}$ \\
\hline & + & + & Instability & $\begin{array}{c}v_{2}+v_{5}<0 \\
C+v_{2}+v_{5}-v_{6}>0\end{array}$ \\
\hline & - & & Saddle Point & $v_{2}+v_{5}>0$ \\
\hline \multirow{3}{*}{$(1,1,0)$} & + & - & ESS & $\begin{array}{c}v_{5}>0 \\
-v_{1}+v_{2}-v_{5}<0\end{array}$ \\
\hline & + & + & Instability & $\begin{array}{c}v_{5}>0 \\
-v_{1}+v_{2}-v_{5}>0\end{array}$ \\
\hline & - & & Saddle Point & $v_{5}<0$ \\
\hline \multirow{3}{*}{$(1,1,1)$} & + & - & ESS & $\begin{array}{c}v_{2}+v_{5}<0 \\
-v_{1}-2 v_{2}-v_{5}<0\end{array}$ \\
\hline & + & + & Instability & $\begin{array}{c}v_{2}+v_{5}<0 \\
-v_{1}-2 v_{2}-v_{5}>0\end{array}$ \\
\hline & - & & Saddle Point & $v_{2}+v_{5}>0$ \\
\hline
\end{tabular}

The calculated value of determinants $(\operatorname{det} J)$ and traces $(\operatorname{tr} J)$ of each equilibrium point of the dynamic system in the Jacobian matrix is shown in Table 2 . When both $\operatorname{det} J>0$ and $\operatorname{tr} J<0$ are satisfied, the equilibrium point is ESS.

Table 2. Stability analysis between the government, enterprise, and consumer.

\subsection{Results}

Based on the stepwise analysis above, the evolutionary stability conditions can be deduced as that the decision-making process of any players in the tripartite game is influenced by the decisions of the rest of the parties.

According to the game analysis model above, it obtains the following results:

$(1)(0,0,0),(0,1,0)$ are saddle points in any case. For $(0,0,1)$, it is instability when $-C+v_{2}+v_{4}-v_{6}>0$. If $v_{5}>0$ and $C+v_{5}+v_{6}>0,(1,0,0)$ is an instability point. Furthermore, it is the saddle point when $v_{5}<0$. Similarly, we can find other unstable points and saddle points under different conditions.

(2) With the help of dynamic evolutionary game theory, we can find the ESS after certain conditions are satisfied. 
While $-C+v_{2}+v_{4}-v_{6}<0$, i.e., when $G_{2}-G_{1}-C-\left(G_{3}-P_{2} Q_{2}\right)<0$, the point $(0,0,1)$ is an ESS. The three-party game decisions are, respectively, (no supervision, controlled placement, consumption). The government does not interfere in the bicycle-sharing market. The enterprise rationally and orderly launches the bicycle-sharing. Consumers choose to use it. There is no regulatory cost for the government. The launch plan formulated by the bicycle-sharing companies can meet the needs of consumers without being punished by the government. In this case, the controlled placement of bicycles is in line with the company's sustainable development. The consumer strategy can strengthen the body and have a positive impact on the economic environment.

When $v_{1}-2 v_{2}-v_{4}<0$, i.e., when $\left.F+I_{1}+I_{2}-2\left(P_{2} Q_{2}-P_{1} Q_{1}\right)-\left(G_{2}-G_{1}\right)\right]<0$, the point $(0,1,1)$ is an ESS. The three-party game decisions are, respectively, (no supervision, massive placement, consumption). The government does not regulate the bicycle-sharing market. The company launches bicycle-sharing massively. Consumers choose to consume. The government's non-regulatory strategy keeps companies from being punished for large-scale placement. Demand in the market and unregulated government make the bicycle-sharing market become a target that companies are aiming to gain. The monetary benefits and reputation brought by the massive placement of the bicycle-sharing companies are greater than that of controlled placement. At this point, the company's investment in a large number of bicycles has become its optimal choice. Currently, the enterprise implements the strategy of "winning by quantity." This gradually forms a "buyer's market," which is good for the consumers. Therefore, consumers should choose to use bicycles.

When $v_{2}+v_{5}<0$ and $C+v_{2}+v_{5}-v_{6}<0$, i.e., when $P_{2} Q_{2}-P_{1} Q_{1}+G_{2}-G_{1}-F<0$ and $C+P_{2} Q_{2}-P_{1} Q_{1}+G_{2}-G_{1}-F-\left(G_{3}-P_{1} Q_{1}\right)<0$, the point $(1,0,1)$ is an ESS. The three-party game decisions are, respectively, (supervision, controlled placement, consumption). The government implements policy supervision on the bicycle-sharing market. The enterprise places a reasonable bicycle. Consumers choose to use bicycles. Because the government oversees the bicycle-sharing market, they increase penalties for violations. If the company relies on a large number of bicycles to compete for the market at this time, it will not only face huge operating and management costs but also receive large fines. Orderly delivery of bicycles is more in line with the company's strategic requirements. As far as consumers are concerned, the orderly launch of the enterprise and the government's regulatory assistance make the consumption become the best decision.

When $v_{5}>0$ and $-v_{1}+v_{2}-v_{5}<0$, i.e., when $G_{2}-G_{1}-F>0$ and $-\left(F+I_{1}+I_{2}\right)+P_{2} Q_{2}-P_{1} Q_{1}-$ $\left(G_{2}-G_{1}-F\right)<0$, the point $(1,1,0)$ is an ESS. The three-party game decisions are (supervision, massive placement, no consumption). The government regulates the bicycle-sharing market. The company launches bike-sharing services massively. However, consumers do not use their services. Because penalties for companies that place vehicles disorderly generate more benefits than regulatory costs, the government chooses the regulatory strategy. Although companies will be punished, a large number of bicycles will not only gain market share but also create a brand identity. The intangible benefits generated by a large amount of investment could meet the company's sustainable development requirement. At this time, the sharing market is subject to government supervision, but corporate decisions will increase the probability that consumers encounter damaged bicycles, and consumers' riding experience will be deteriorated sharply.

When $v_{2}+v_{5}<0$ and $-v_{1}-2 v_{2}-v_{5}<0$, i.e., when $P_{2} Q_{2}-P_{1} Q_{1}+G_{2}-G_{1}-F<0$ and $-\left(F+I_{1}+I_{2}\right)-2\left(P_{2} Q_{2}-P_{1} Q_{1}\right)-\left(G_{2}-G_{1}-F\right)<0$, the point $(1,1,1)$ is an ESS. The three-party game decisions are (supervision, massive placement, consumption). The government regulates the bicycle-sharing market. The enterprises launch bicycle-sharing irrationally. Consumers choose to use bicycles. The benefits of penalizing companies that place vehicles disorderly are greater than the cost of supervision making the government choose the supervision strategy. A large number of bicycles placed enables the enterprise to gain market share and create a brand identity outweighing government penalties. At this time, the revenue created is far greater than the cost of expenditure. A large amount of investment in bicycle conforms to the company's sustainable development. Although consumers 
may encounter broken bicycles, their search costs drop significantly. Reduction in search cost makes it convenient for consumers to find a suitable bicycle in line with the focal concept of the sharing economy.

\section{Discussions}

Through the equilibrium analysis and replication dynamic analysis of the government, the company, and the consumers, this paper considered these parties as an organic whole and identified the strategic balance points among them. Table 3 presents the discussions between the three parties.

Table 3. Discussions between the government, enterprise, and consumer.

\begin{tabular}{|c|c|c|c|}
\hline Government & Customer & Company & Strategy \\
\hline No supervision & Consumption & Controlled placement & $\begin{array}{l}\text { Without government regulation, } \\
\text { the company's sustainable } \\
\text { strategy is to supply on demand. }\end{array}$ \\
\hline Supervision & Consumption & Controlled placement & $\begin{array}{l}\text { The company should provide } \\
\text { consumers with quality } \\
\text { bicycle-sharing services following } \\
\text { government regulations. }\end{array}$ \\
\hline No supervision & Consumption & Massive placement & $\begin{array}{l}\text { In addition to placing a large } \\
\text { number of bicycles, the company } \\
\text { also needs to pay attention to the } \\
\text { problems caused by the } \\
\text { massive placement. }\end{array}$ \\
\hline Supervision & No consumption & Massive placement & $\begin{array}{l}\text { When market demand is } \\
\text { insufficient, the company should } \\
\text { pay attention to government } \\
\text { policies and adopt new } \\
\text { technologies to attract consumers. }\end{array}$ \\
\hline Supervision & Consumption & Massive placement & $\begin{array}{l}\text { The company should produce } \\
\text { bicycles that meet the needs of } \\
\text { consumers to enhance the } \\
\text { company's competitiveness. }\end{array}$ \\
\hline
\end{tabular}

When the bicycle-sharing enterprise chooses to place the bike reasonably, self-regulation and strict implementation by the enterprises can largely reduce problems of "bottom-line competition" among the enterprises [29] and promote the healthy development of enterprises. In point (no supervision, controlled placement, consumption), the government gives up supervision of the market. For the consumers, the use of bicycle-sharing not only help them keep fit but also respond to the national call of "green economy, green travel."

Considering that arbitrary delivery will be subject to government supervision and penalty, the bicycle-sharing enterprise will choose to use advanced information technology to optimize the inventory and delivery of the bicycle-sharing in point (supervision, controlled placement, consumption). It is used to ensure the normal operation of their business and build a positive brand identity [30-32]. As the leader and defender of national policy, the government should monitor and control the bicycle-sharing market and enterprise timely, ensuring the effectiveness of government operation. When the government supervision fails, it has to pay for the remedial measures. From the perspective of risk conservative strategy, the government will choose to supervise the market. Considering that the government has supervised the enterprise, and the deployment of the bicycle-sharing on the market is reasonable, the consumer will be more inclined to use bicycle-sharing. These three parties will develop a benign ecosystem based on their interests and social environment.

The government's non-regulatory strategy has fostered bad corporate competition. The enterprises are unsupervised and they place the bicycle wherever they wish to gain market share and make higher profits. The bicycles spreading around the city not only mitigate the tension of public transport 
and roads but also reduce the search costs of consumers [29]. Form point (no supervision, massive placement, consumption), a large number of bicycles on the market can generate visible benefits. However, there are also inevitable problems requiring the enterprises' attention: extensive placement of bicycles disrupts market order, undermines social credibility, and causes a nonrefundable deposit, leading to a chaotic market environment [33].

The government chooses the supervision strategy from the perspective of avoiding costs. However, considering that the current bicycle-sharing market supervision policy is not mature enough in China, the controlled placement of the bicycles may significantly reduce profit margins. Thus, the company has the chance to choose a massive placement. The vicious competition between the bicycle-sharing enterprises has encouraged consumers to use bicycle-sharing enormously. The disorderly parking, lanes occupation, and private locks installation have disturbed the social order and inflicted damage on the interests of the public [29]. Facing the disorders of the bicycles on the street, the consumers might abandon this "green travel" approach. At this point (supervision, massive placement, no consumption), although the company makes profits, it will gradually lose consumer trust.

Similarly, to avoid the negative effects of non-regulation, the government will strictly supervise the bicycle-sharing enterprises and the market. However, the enterprises consider it profitable to place large quantities of bicycles on the market, which generates more benefits than the penalty by the government. The way the enterprise expands the market can reduce the search cost of the bicycles for the consumer, while the government's supervision can protect the rights of consumers. The best strategy for the consumer is to use shared bicycles. There is no doubt that at this point (supervision, massive placement, consumption), massive placement of bicycles can help the company obtain competitive advantages in the market.

For the government, when the expected benefits of government supervision of the sharing market and the market disturbance caused by the government's monitoring of the market are greater than the cost of supervision, i.e., when $x \rightarrow 1$, the government shall supervise the market. Therefore, increasing the fine $F$ to the enterprise and lowering the government's monitoring $\operatorname{cost} C$ will help promote the government's choice of "supervision".

For the consumer, when consumer's benefit from riding a bicycle $\left(G_{3}, G_{4}\right)$ is greater than the cost they pay $\left(P_{1} Q_{1}, P_{2} Q_{2}\right)$, they might decide to use the bicycles, i.e., when $z \rightarrow 1$. Because the consumer is the direct user of the shared bicycles, their behavior affects the workload of the post-maintenance of the bicycles. The consumer will pay more attention to the convenience of cycling and the impact of the development of the bicycle-sharing market on their living environment.

For the company, when the ratio of the expected cost paid by a company to place massive bicycles and the revenue obtained is smaller than the consumer's consumption probability, i.e., $y \rightarrow 1$, it might choose to place the bicycles massively. Business launch decisions should fully consider consumers' decision-making income $P_{2} Q_{2}-P_{1} Q_{1}$. Therefore, in consideration of losses such as government fines and negative images, the decision-making behavior of the enterprise needs to fully capture consumer behavior.

From the results, it is inappropriate to consider that the massive bicycles will win the market for the bicycle-sharing company in China without considering the choice of the government and consumer. Firstly, due to the imperfect mechanism of the bicycle-sharing market and government supervision as well as the "quasi-public goods" nature of the bicycle-sharing, it is easy to generate the "tragedy of the commons [34]." The massive placement will provoke a "bottom-line competition" among the companies, undermining the capacity structure of the sharing market and increasing the possibility of being punished by the authorities. Secondly, blindly catering to consumer's "preferences" will lead to their destruction and private possession of the bicycles, resulting in a waste of enterprise resources and difficulties in maintaining bicycle-sharing [23]. The damage to the bicycle is mixed with the "broken window effect." That is, if a bicycle has some minor problems and cannot be repaired in time, other problems will appear fast until it is no longer able to serve the consumers [34]. The "broken window effect" causes an unsatisfied travel experience, easily causing consumers to lose faith in the 
bicycle-sharing company. Both the utilization rate and maintenance rate of bicycles will become obstacles to the company's sustainable development strategy. Malfunctioning bicycles are an important factor restricting bicycle-sharing development [7].

The enterprise should maintain the bicycle-sharing business in the context of sustainable development. Expanding the scale of the system is unable to improve the performance of the bicycle-sharing system [35]. Firstly, companies should pay attention to government policies in advance when making investment decisions and understand the government's attitude towards market supervision. This can help companies avoid penalties for regulation violations. In addition, the company should combine big data analysis to clarify market-consumer preferences and capacity in various regions. "Demand determines supply." This can help the company to flexibly and efficiently put bicycles in line with its sustainable development. Secondly, as the policymaker, the government should enact relevant policies to promote the healthy development of the sharing economy market. In addition to formulating corresponding regulations and basic service standards, encouraging market mechanisms to solve the risk problems in sharing, it is necessary to innovate the concept of supervision, be patient with the development of the sharing economy, and create a supportive environment. Finally, the consumers are the direct users of the shared bicycles, and their behavior affects the workload of post-maintenance. From this perspective, the consumer should build their self-discipline, enhance moral literacy, and use bicycles appropriately.

\section{Conclusions}

The study proposed a game-theoretic model featuring bicycle-sharing and the company's sustainable development to investigate the bicycle-placement strategy of the company. The study analytically derived the optimal delivery strategy under these five conditions by showing the equilibrium among the government, consumers, and the company. The above analysis showed that the company's sustainable development requires the number of bicycle-sharing to vary to the market conditions. According to the strategic actions of the government and consumers, the company should flexibly arrange the bicycle placement. The results also showed that government regulation plays a dominant role in the development of the bicycle-sharing company determining the number of bicycles needed in the market.

When analyzing the relationship between the placement of a bicycle-sharing company and the company's sustainable development, the study not only considered the fines generated by government supervision [36] and consumer consumption income [37] but also the potential impact of the market situation of bicycle-sharing on each subject. Both "tangible income" and "intangible income" were included in this study. In this way, the study would be able to advance the understanding of the company's decision-making process and provide guidelines for the company's sustainable operation.

There are several limitations to this study. Bicycle-sharing is a new phenomenon that meets the requirements of "green environmental protection." Standardizing the bicycle-sharing market can reduce certain urban traffic problems. This paper focused on the issue of bicycle delivery in the development of the bicycle-sharing market using the evolutionary game theory. However, the study did not take into consideration other issues in evolutionary game analysis, such as path optimization, price, and market competition. In addition, this paper only modeled the bicycle-sharing market development strategies analytically while leaving the empirical examination of the results as a future research direction.

Author Contributions: Conceptualization, J.Z. and H.W.; methodology, J.Z.; validation, H.W.; formal analysis, H.W. and J.Z.; writing-original draft preparation, J.Z.; writing-review and editing, H.W., Y.H., and Y.M.; visualization, J.Z.; supervision, H.W.; project administration, J.Z.; funding acquisition, H.W. All authors have read and agreed to the published version of the manuscript.

Funding: This research was funded by the National Natural Science Foundation of China with grant number 71771177. It was also granted by the University Innovation Fund from the Science and Technology Development Center of the Ministry of Education (2019J01012). 
Acknowledgments: The authors would like to acknowledge the contribution of all partners of this study and thank the anonymous referees for their useful criticism as well as valuable suggestions.

Conflicts of Interest: The authors declare no conflict of interest.

\section{References}

1. Fishman, E.; Washington, S.; Haworth, N. Bike share's impact on car use: Evidence from the United States, Great Britain, and Australia. Transp. Res. Part D Transp. Environ. 2014, 31, 13-20. [CrossRef]

2. Frade, I.; Ribeiro, A. Bicycle sharing systems demand. Procedia-Soc. Behav. Sci. 2014, 111, 518-527. [CrossRef]

3. Frade, I.; Ribeiro, A.; Rose, J. Bike-sharing stations: A maximal covering location approach. Transp. Res. Part A Policy Pr. 2015, 82, 216-227. [CrossRef]

4. Shaheen, S.; Guzman, S.; Zhang, H. Bicycle sharing in Europe, the Americas, and Asia. Transp. Res. Rec. J. Transp. Res. Board 2010, 2143, 159-167. [CrossRef]

5. Wen, L.; Junfang, S.; Liyun, X. Analysis of the Game among the Government, Businesses, and Consumers at the Backdrop of the Sharing Economy-the Operation of Sharing bicycles as an Example. J. Jianghan Univ. 2018, 35, 75-85+128.

6. Bullock, C.; Brereton, F.; Bailey, S. The economic contribution of public bike-share to the sustainability and efficient functioning of cities. Sustain. Cities Soc. 2017, 28, 76-87. [CrossRef]

7. Du, M.; Cheng, L. Better Understanding the Characteristics and Influential Factors of Different Travel Patterns in Free-Floating Bike Sharing: Evidence from Nanjing, China. Sustainability 2018, 10, 1244. [CrossRef]

8. Qiu, L.-Y.; He, L.-Y. Bike Sharing and the Economy, the Environment, and Health-Related Externalities. Sustainability 2018, 10, 1145. [CrossRef]

9. Brinkmann, J.; Ulmer, M.W.; Mattfeld, D.C. Inventory routing for bike sharing systems. Transp. Res. Procedia 2016, 19, 316-327. [CrossRef]

10. Jasper Schuijbroek, R.H. Inventory rebalancing and vehicle routing in bike sharing systems. Eur. J. Oper. Res. 2017, 257, 992-1004. [CrossRef]

11. Brinkmann, J.; Ulmer, M.W.; Mattfeld, D.C. Dynamic Lookahead Policies for Stochastic-Dynamic Inventory Routing in Bike sharing Systems. Comput. Oper. Res. 2019, 106, 260-279. [CrossRef]

12. Lin, J.R.; Yang, T.H. Strategic design of public bicycle sharing systems with service level constraints. Transp. Res. Part E Logist. Transp. Rev. 2011, 47, 284-294. [CrossRef]

13. Çelebi, D.; Yörüsün, A.; Hanife, I. Bike sharing system design with capacity allocations. Transp. Res. Part B Methodol. 2018, 114, 86-98. [CrossRef]

14. Faghih-Imani, A.; Hampshire, R.; Marla, L.; Eluru, N. An empirical analysis of bike sharing usage and rebalancing: Evidence from Barcelona and Seville. Transp. Res. Part A Policy Pr. 2017, 97, 177-191. [CrossRef]

15. Dell"Amico, M.; Hadjicostantinou, E.; Iori, M.; Novellani, S. The bike sharing rebalancing problem: Mathematical formulations and benchmark instances. Omega 2014, 45, 7-19. [CrossRef]

16. Pal, A.; Zhang, Y. Free-floating bike sharing: Solving real-life large-scale static rebalancing problems. Transp. Res. Part C Emerg. Technol. 2017, 80, 92-116. [CrossRef]

17. De Chardon, C.M.; Caruso, G.; Thomas, I. Bike-share rebalancing strategies, patterns, and purpose. J. Transp. Geogr. 2016, 55, 22-39. [CrossRef]

18. Si, H.; Shi, J.G.; Tang, D.; Wu, G.; Lan, J. Understanding intention and behavior toward sustainable usage of bike sharing by extending the theory of planned behavior. Resour. Conserv. Recycl. 2020, 152, 104513. [CrossRef]

19. Yang, F.; Ding, F.; Qu, X.; Ran, B. Estimating Urban Shared-Bike Trips with Location-Based Social Networking Data. Sustainability 2019, 11, 3220. [CrossRef]

20. Yao, Y.; Liu, L.; Guo, Z.; Liu, Z.; Zhou, H. Experimental Study on Shared Bike Use Behavior under Bounded Rational Theory and Credit Supervision Mechanism. Sustainability 2018, 11, 127. [CrossRef]

21. Jie, J.; Jun, Z.; Qiuhong, Z. Supervision after certification: An evolutionary game analysis for chinese environmental labeled enterprises. Sustainability 2018, 10, 1494.

22. Yuqiong, W.; Shunping, J.; Sijia, Z.; Jun, L. Reward and Punishment Strategy for Bicycle-sharing Parking Based on the Game Theory under the Influence of Position Recognition Rate. J. Transp. Syst. Eng. Inf. Technol. 2019, 19, 101-107. 
23. Qian, X.; Kong-Tuan, L.; Economics, S.O.; University, F.N. Evolutionary game analysis on the main stakeholders in the development of public-sharing bikes specification-based on stakeholder perspective. J. Southwest Jiaotong Univ. 2018, 19, 31-40.

24. Xiaoli, T.; Zhijie, S. Evolutionary game analysis of the cooperative consumption behavior of the participants in the sharing economy. Enterp. Strategy 2019, 461, 68-74.

25. Minhui, Z.; Zhuowang, G.; Danping, Q. Research on the development of Shared bikes from the perspective of social co-governance. Enterp. Reform Manag. 2019, 7, 11-12, 52.

26. Ma, S.H.; Yang, Y.; Wang, Y.Q.; Han, S.S. Public bicycle development under the influence of bike-sharing. J. Transp. Syst. Eng. Inf. Technol. 2018, 18, 231-236+244.

27. Ke, J.; Daming, Y.; Ryan, M.; Zhendong, 1. Implementation of a multi-agent environmental regulation strategy under Chinese fiscal decentralization: An evolutionary game theoretical approach. J. Clean. Prod. 2019, 214, 902-915.

28. Esmaeili, M.; Allameh, G.; Tajvidi, T. Using game theory for analysing pricing models in closed-loop supply chain from short- and long-term perspectives. Int. J. Prod. Res. 2015, 54, 1-18. [CrossRef]

29. Yuan, T. Exploration and prevention of "bottom line competition" of Shared bikes. Price Theory Pract. 2017, 3, $38-42$.

30. Ho, S.C.; Szeto, W.Y. Solving a static repositioning problem in bike-sharing systems using iterated tabu search. Transp. Res. Part E Logist. Transp. Rev. 2014, 69, 180-198. [CrossRef]

31. Caggiani, L.; Ottomanelli, M. A modular soft computing based method for vehicles repositioning in bike-sharing systems. Procedia-Soc. Behav. Sci. 2012, 54, 675-684. [CrossRef]

32. Caggiani, L.; Ottomanelli, M. A dynamic simulation based model for optimal fleet repositioning in bike-sharing systems. Procedia-Soc. Behav. Sci. 2013, 87, 203-210. [CrossRef]

33. Yi, L.; Jiechang, X. Sharing economic theory and policy research trends. Econ. Perspect. 2016, 4, $118-127$.

34. Yali, H.; Zhiqiang, W. Common Construction, Governing and Sharing: Intelligent Management Path of Sharing Bike by Big Data Supporting. Manag. Rev. 2019, 31, 251-256.

35. Yujun, Y.; Hanhui, H. The Research on the Governance Countermeasure of Shared Bicycle based on Multi-theoretical Perspective. Techno-Econ. Manag. Res. 2019, 2, 86-91.

36. Guohua, Q.; Xue, L.; Weihua, Q.; Qiang, Z. Evolutionary Game Analysis of Development Strategies of Government and Game Enterprises under Public Participation. Chin. J. Manag. Sci. 2020, 1-12. [CrossRef]

37. Kung, L.C.; Zhong, G.Y. The optimal pricing strategy for two-sided platform delivery in the sharing economy. Transp. Res. 2017, 101C, 1-12. [CrossRef]

(C) 2020 by the authors. Licensee MDPI, Basel, Switzerland. This article is an open access article distributed under the terms and conditions of the Creative Commons Attribution (CC BY) license (http://creativecommons.org/licenses/by/4.0/). 